\title{
WHICH CLAUSE TYPE DO YOU USE IN YOUR CONVERSATION?
}

\author{
SUPARJAN ${ }^{1}$ \\ (Dosen Universitas Tanjungpura)
}

\begin{abstract}
The objective of this article is to discuss the classification of clause type in English Grammar commonly used for either formal or informal conversation. It cannot be avoided that people always tell, ask, command, request and perform other acts for their daily communicative purpose. These kinds of acts are commonly referred as Clause Type. Basically, there are four terms of clause type in English namely declarative, interrogative, exclamative, and imperative. Those terms of clause type are employed to accomplish different communicative intentions. Moreover, knowing Clause type in English may contribute a clear understanding during having English intercourse with the speakers.
\end{abstract}

\section{Introduction}

In daily conversation, people say something (or many things), ask, request, command, and respond each other. During this process of communication, various types of clauses are definitely employed to simply say, to further request or to directly or indirectly command. It is interesting to discover what type of clause type people use in expressing their thought in English conversation.

This article discusses clause types, particularly its classification in English grammar. Clause type can be defined as a series of strategies used for constructing statements originating from the basic declarative clause to accomplish different communicative intentions (Stebbins, 2008). In clause type system, a range of different clauses to express different communicative purposes are termed as declarative, interrogative, exclamative, and imperative clauses. A declarative clause is generally utilized for making a statement; an interrogative clause will be employed to create a question; an exclamative clause will be used to construct an exclamation; and an imperative clause is usually associated with directives, that is, commands or request. All of these clauses are named syntactic categories as they are viewed from the position of subject, the formation of verb phrase.

${ }^{1}$ Suparjan adalah dosen Universitas Tanjungpura 
In this article, the above four series of clause type are discussed respectively in the following sub-chapters. The elaboration will relate a range of strategies differently used in those four major terms of clause type namely declarative, interrogative, exclamative, and imperative in order to accomplish different communicative intentions.

\section{Clause Type}

As pointed out in the introduction of the article that the major term of clause type can be divided into four major series; declarative, interrogative, exclamative, and imperative (Huddleston , 2002) and this article will elaborate those four series of clause type. Knowing clause types in English will facilitate us in expressing appropriate statements, comments, commands or responses in English intercourse in order to minimize misunderstanding among the speakers.

\subsection{Declaratives}

Declaratives are characteristically used to make statements. They are the unmarked clause type (Huddleston, 2002). Declaratives can be constructed in affirmative or negative form. They are used to make statements about how things are and how they are not. The common word order is subject (s) + verb (v) $+\mathrm{x}$

Affirmatives

She picked me up yesterday.

S V X

Some courses begin in February.
Negatives

She didn't pick me up yesterday.

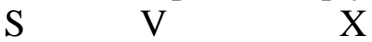

Some courses don't begin in February.

$\mathrm{S} \quad \mathrm{V}$

$\begin{array}{llllll}\text { S } & \text { V } & \text { X } & \text { S } & \text { V } & \text { X }\end{array}$

Declarative statements also are sometimes used as questions or requests in informal situation marked by higher intonation:

Questions
A: Those are the only tickets left?
B: Yes, just those two.

Requests

A: You could pass me the spoon. That would be helpful.

$\mathrm{B}$ : This one? 
According to Huddleston (2002) in uttering a declarative clause, someone should normally commit himself to the truth of intention that is used to communicate. In the usage of declarative clause, someone will often unconsciously involve with illocutionary act for many verbs indicate a kind of illocutionary act such as promise, request, order, advise, thank, apologies, etc. Illocutionary act refers to any types of act that someone uses in uttering his intention (Huddleston, 2002). Now let's identify the following examples:

a. Untan will hold a linguistics seminar in 2014 where prominent linguists all over Indonesia will be invited.

b. The postgraduate students of English department must avoid plagiarism to maintain the purity of their work.

In (a) and (b), a declarative have a modal auxiliary as will and must. Both of them can be used with illocutionary force of directive (Huddleston, 2002).

\subsection{Interrogatives}

Interrogative clause shall be used for posing a question and in interrogative clause, there are two major types of clause, Wh interrogative and Non-wh interrogative and they are illustrated below:
a. Why is she late?
Wh interrogative
b. Is she ill?
Non-wh interrogative

The type demonstrated in (a) is marked by the existence of one of the interrogative words why then in (b) belongs to the unmarked interrogative type, the non-wh interrogative as there is no interrogative word. From the sample above, it can be tracked that if someone use wh interrogative in uttering his intention, there is a possibility that he would like to seek for information from a question. Meanwhile, if someone delivers his idea with non-wh interrogative, it is apparently that the person already had in mind that the answer will be yes or no.

Furthermore, in interrogative clause type, there is one term that attracts more attentions that is $\mathrm{x}$-questions. Think about the sets of answers to a question bellow:

a. Who broke the window?

In question (a), it can be identified that the answer to the question can be more than one. The answers can be "I broke the window", "Tejo broke the window", 
"the plumber broke the window" and so forth. According to Huddleston (2002), all of them are semantic forms as "x broke the window" provide different values for variable $\mathrm{x}$. This is called $\mathrm{x}$-questions.

The other term in interrogative clause type that not everyone may recognize is alternative questions. Now let's analyze the question below:

b. Is he alive or dead?

In question (b) there will be two simply alternative answers, he is alive or he is dead. The answer to this question is derivable from the question itself. The main matter is selecting between two alternatives given in the question. Therefore, alternative question is a term commonly given to such questions.

\subsection{Exclamatives}

Exclamatives are naturally used to make exclamatory statements and they are marked by one or other of the wh words how and what. According to Huddleston (2002) how is characterized to be more formal and careful style than what. A speaker that uses exclamative clauses usually wants to express a heightened evaluation of a situation.

a. What a smart lecturer he is!

b. How nice he explains!

In (a) exclamative what is a determinative, syntactically it engages determiner position. If it is viewed from semantics viewpoint, wh what is concerned with degree not identity. Meanwhile in (b) wh word how is generally functions as a degree of modifier of adjective, adverb or many, much, few, little. In addition, wh word how also can function as head of an Adv on its own: How we laughed! Exclamative clauses usually have one of the following word orders:

What + noun + subject + verb (e.g. What a big house it is!)

How + adjective or adverb + subject + verb (e.g. How clear the teacher explains!)

However, in more informal situations, we can simply omit the subject and the verb as in the following sentences:

a. What a pleasant environment!

b. What nice weather!

c. How wonderful! 


\subsection{Imperatives}

Imperatives are usually correlated with directives, that is, commands or requests. If it is viewed from syntactic category, they are not similar with declaratives. They can be identified by the omission of the second person subject, the use of the auxiliary $d o$ with the verb be in negation or verb with restricted use of modal auxiliaries. See the differences between a declarative and an imperative statement below:

a. You must come in the class on time. (declarative)

b. Come in the class on time. (imperative - no $2^{\text {nd }}$ person pronoun; no modal)

c. You need to clean this room regularly. (decalarative)

d. Clean this room regularly (imperative - a command; no $2^{\text {nd }}$ person pronoun)

e. You have to tell me the secret of your ageless look. (declarative)

f. Please tell me the secret of your ageless look. (imperative - a request; no $2^{\text {nd }}$ person pronoun, with an additional 'please')

Imperative clauses can be affirmative or negative. We make negative imperatives with auxiliary verb $d o+$ not. The contracted form don't is very common in speaking:

Affirmative Negative
a. Go!
Don't go!

b. Leave the door open.

Don't leave the door open.

However, sometimes we use you (subject pronoun- $2^{\text {nd }}$ person pronoun) with an imperative clause to make a command stronger or to strengthen a contrast. It can sometimes sound impolite:

a. Don't you ever read my letters again. (make the command stronger and can sound impolite)

b. You wash, I'll dry. (to strengthen a contrast).

In informal speaking, we can use an indefinite subject (e.g. someone, somebody, no one, nobody, everyone, everybody) with an imperative:

a. No one move. Everyone stay still.

b. Somebody say something. I need an opinion.

\section{Interrogative tags}

Interrogative tag is a special kind of non wh interrogative. It can be attached to declarative, exclamative, or imperative clauses. According to Huddleston (2002), there are two types of tag questions: reversed polarity tags and 
constant polarity tags. In reversed polarity, the polarity of the tag is opposite to the polarity of the clause. Thus, if the clause is positive, the tag will be negative. Reversed polarity tags are often used for asking confirmation:

a. Azzam likes linguistics, doesn't he?

b. Dinda took four subjects last semester, didn't she?

In addition, Huddleston (2002) argues that raising or falling information in reversed polarity construction is one of a significant aspect to be considered as with a rise on the tag, the construction indicates that someone is inclined to believe the proposition expressed in the declarative. It indicates one's commitment to the truth of proposition expressed in declarative and also seeks for one's confirmation.

Moreover, constant polarity tags have the same polarity value as the clause. So, a positive clause will have a positive tag. Constant polarity tags are used to express surprise:

c. Naida likes the subject, does she?

Lastly, Huddleston (2002) proposes that when in fact there is no doubt about the truth of the proposition encoded in declarative, constant polarity construction is often used. It is something to express some kind of disapproving attitude on the part of speaker.

\section{Echo Questions}

An echo question is a question that occurs in the turn after a repairable utterance, and repeats the portion felt by the speaker to need repair. (Hartmann and Stork, 1972).

B's question in the following exchange is an echo question.
A: I need a new material for my class.
$\mathrm{B}$ : A material?
A: I mean for my linguistics class.

In addition, Sadock \& Zwicky (1985) argue that we use echo questions to show interest or surprise. For this purpose, the listener makes a short question using the auxiliary or helping verb of the statement the speaker has just said. 
$\mathrm{C}$ : He is attending a wedding of his ex-wife at this moment.

D. Is he?

C: They bought a new Television set last week.

D: Did they?

C: I work as a lecturer in a state university in Pontianak.

D. Do you?

C: My wife has finally decided to join that seminar.

D. Has she?

\section{Speech Act}

What is speech act? Speech act is a theory in pragmatics that concerns with ways in which words can be used not only to present information but also to carry out actions (Kaburise, 2012).

Speech-act theory is first introduced by Oxford philosopher J.L. Austin in his book entitled How to Do Things With Word in 1962. This theory is then developed by American philosopher J.R. Searle. According to Austin's theory (1962), there are three kinds of meaning for what we express. The first is propositional meaning in which the literal meaning of is what is said such as "it's hot in here". The second form of meaning is illocutionary meaning. The meaning of this intended act is as the social function of what is said. For instance, 'It's hot in here' can mean an indirect request for someone to open the window or an indirect refusal to close the window because someone is cold or a complaint implying that someone should know better than to keep the windows closed (expressed emphatically). The last is elocutionary meaning. The purpose or the effect of what is said 'It's hot in here' can result in asking someone to open the windows.

6. Correlation between clause type and speech act

Huddleston (2002) argues that there is a correlation between clause type and speech act and the resulting speech act is not absolute, for example an interrogative clause (such as, How many times have I told you to close the door?) or declarative clause (such as, it's cold in here) can be used as a type of directive (= close the door). Here are some other examples:

a. Mel, this ice-cream is really tasty. 
From the above example (a), it can be analyzed that the form of the clause is declarative and the type of speech act is making a command that is to ask someone to eat the ice cream.

b. How I enjoy traveling in Malaysia, Darl!

In other cases, for example in (b), the form of clause type is exclamative and the intended speak act is also making a command, that is in the example (b), the woman can mean that she is actually asking her husband to go to Malaysia again.

c. Eat some ice-cream, Mel.

If we look at the example above (c) in glance, we can conclude that the form of clause type is imperative and the intended speech act is making command too.

Another important thing that must be paid attention in identifying intended intention is intonation. Intonation play a key role as an important marker of the speech act involved. In the case of questions, the clause is usually associated with rising intonation. In some cases intonation can be used to identify that a clause is a question, even if syntactically it has the form of a declarative. The question mark indicates the intonation of the clause, not the clause type. Example:

a. Abel wants a lion for a pet?

b. You're sure you heard right?

It is also important to think that a sentence may contain clauses of more than one type. The examples below show two compound sentences that contain clauses with different structures:

Example:

a. Amta likes meat ball, but does Tayam like it too?

b. I thought Amta liked meat ball, or was it Chicken noodles?

\section{Conclusion}

In general, there are four kinds of clause types in English grammar, declarative, interrogative, exclamative, and imperative. Each clause type has different meanings both syntactically and semantically. Therefore, one needs to 
consider the intended meaning of his or her interlocutor's expressing statements. As what has been discussed, the way someone utters a statement can determine a different intended meaning of the utterance even though structurally the form of the sentence or clause is similar.

\section{Bibliography}

Austin, J. L. (1962). How to do things with words. Oxford: Oxford University Press.

Hartmann, R.R.K., and F.C. Stork. (1972). Dictionary of language and linguistics. London: Applied Science.

Huddleston, Rodney \& Geoffrey K. Pullum (2002). The Cambridge Grammar of the English Language. Cambridge University Press

Kaburise, Phyllis. (2012). Recognising Speech Acts. Journal for Language Learning. 28 (1) : 36-48 http://dx.doi.org/10.5785/28-1-118.www. perlinguam. journals.ac.za

Sadock, J. M. and A. Zwicky. 1985. Speech act distinctions in syntax. In Shopen, T., ed., Language Typology and Syntactic Description. Cambridge: Cambridge University Press, 155-196.

Stebbins, Tonya. (2008). Grammarpedia: Online English Grammar Resource. Retrieved from http://languagetools.info/grammarpedia/clausetype.htm 